\title{
Some Aspects of Gerontology in the United States
}

\author{
STANLEY R. MOHLER, M.D.
}

$\mathrm{T}$ ODAY in the United States the declining athletic prowess which accompanies aging, particularly after age 40, is far less significant occupationally to laborers as a group than it was two generations ago and earlier. This fact is a direct result of technological change, a development which, in effect, has provided the industrial energy requirements of the United States with calories derived for the most part from nonmuscle sources.

On the other hand, the laborer, white collar worker, professional person, and other categories of citizens find that although certain problems of aging, serious in 1900, are no longer so pressing, other problems have emerged which may in the long run prove far more difficult to resolve. Some will never be solved or compromised to the satisfaction of all.

\section{Health}

Cardiovascular and cerebrovascular disease, of which atherosclerosis constitutes the most frequently found pathological change, is the leading cause of death in the age group over 65 years. Cancer is second. Together these conditions account for more than three-fourths of the deaths of older persons. Acute respiratory infectious diseases are next most numerous among causes of death, followed by the category of accidents. Falls, motor vehicle acci-

Dr. Mohler is medical officer of the Center for Aging Research, National Institutes of Health, Public Health Service. The article is based on a paper presented at the Section on Geriatrics and Gerontology, Pan American Medical Association, Mexico City, May 4, 1960. dents, and fires comprise 85 percent of the fatal accidents which occur among the aged.

Several usually nonfatal conditions are common among the aged. Periodontal disease is claiming most of the teeth lost after the age of 35. Cataracts in various stages of development are found in more than half of the individuals over 65. Almost all persons over 65 have some degree of hearing loss. Osteoarthritis is a cause of daily discomfort to many older persons and is particularly bothersome when it occurs in the hips and fingers. Osteoporosis, senile emphysema, and benign prostatic hypertrophy have their highest incidences, as expected, among the geriatric patients.

About 136,000 patients over 65 currently reside in State hospitals for the mentally ill, comprising about 30 percent of the patient load of these institutions. About 90 percent of these patients are diagnosed as "senile brain syndrome" or "arteriosclerotic brain syndrome." These diagnoses are far removed from schizophrenia and the affective disorders, conditions for which the institutions were originally established.

An important consideration in the mental health of the average older person is the fact that the United States has what sociologists have termed a youth-oriented culture. Apparently, the frontier-times respect for high physical capacity, associated with the ability to drop previous modes of life, break with tradition, and start anew, has not yet been replaced by other philosophies. This cultural milieu produces a feeling of inferiority in many older persons. It is thought that tendencies toward mental depression and hypochondriasis may arise on this basis. 
The ease with which he becomes fat plagues the average person in the United States as he ages. It appears that the appetite is one psychophysiological phenomenon which does not decline with age, and it may even become unmanageable. Some have estimated that the average adult is 10 to 15 pounds overweight. The problem with such estimates is that no one has been able to define "ideal weight" adequately.

In the short-stay hospitals of the United States, there is about 1.0 hospital-day per person per year for the age group 25-64. For the age 65 and over bracket, this statistic is 1.8 . Furthermore, those in the over 65 bracket stay an average of 15 days per hospitalization, while those in the 25-64 age group stay 9 days. In chronic disease hospitals, nursing homes, and related institutions the aged occupy the vast majority of the beds.

At present, various methods of meeting the medical expenses of the elderly are receiving national attention. It is apparent that a certain segment of this expense must be met by the community at large. Possibly the community may be able to cut expenditure considerably by investing in certain rehabilitation and home care programs.

\section{Income}

Increases in technological complexity cause the older worker certain difficulties if he should seek a new job. It is quite possible to find that one's skills have become hopelessly outmoded after 30 years' employment in a given occupation.

Recently a congressional subcommittee observed that at least half of the aged in the United States cannot afford decent housing, medical care, or recreation. Also, fixed incomes after retirement, derived from pensions of various types, are often diluted by the effects of inflation.

\section{Retirement}

After a life of busy, gainful employment, free time becomes a heavy burden for the retiree. A search for satisfying pursuits is facing most retired persons.

A number of retired persons are moving to parts of the United States having warm weather the year around. Florida, Arizona, and southern California are the popular areas. We have not yet fully assessed the impact of such moves upon the retiree, particularly when the relocation means loss of touch with lifelong friends, family members, and familiar environments.

A critical factor in retirement is the matter of retaining a feeling of self-respect. When one is no longer a breadwinner, and particularly if one reverts to a dependency status, feelings of uselessness are apt to occur.

\section{Housing}

The new high-rise apartment houses for the elderly may be ideal for some older persons, but certainly not for all. The absence of younger people may be disturbing to many. On the other hand, such facilities do provide a convenient constellation of potential companions.

Three-fourths of the persons over 65 in the United States live in what could be termed a family (living with a spouse, blood relative, or relative by marriage or adoption). Of the remaining older persons, one in five lives with nonrelatives, while four in five live alone.

Today's picture in regard to old folks homes and nursing homes has radically changed, when contrasted with the situation in 1900 . The modern domiciliary institution, particularly the home for the aged, is not a refuge for the indigent. It is becoming a place where enlightened staff members counsel and assist residents in regard to various daily activities. The demand for such facilities still exceeds the supply.

\section{The Family}

Three-generation families present complex social problems. The rapidly growing suburban areas, crowded with houses designed for two adults and two children and characterized by minute yards and inadequate recreational facilities, do not provide places for grandparents.

Nevertheless, it is true that many children must, upon reaching adulthood, take in their aged parents. The conflicts which often characterize such associations can have serious mental health consequences, particularly in societies with rapidly changing ideals. The young 
adult's scorn for his aged parent's beliefs leads to intrafamily strain and feelings of misunderstanding and guilt.

\section{Research}

The health-related aspects of aging are receiving the attention of numerous researchers. However, many believe that the gap between what we need to know about aging and what we do know is so large that much more research is required. To this end, the Federal Government has established various administrative components which spend full time on matters pertaining directly to aging. Many State and local governments have followed suit, and various private organizations which focus on aging have come into existence.

Last year the National Institutes of Health of the Public Health Service granted about $\$ 12$ million to various medical schools and universities for studies on aging. Other agencies and organizations also provided support for gerontological investigations. These efforts must continue and expand, for, like the mythological Hydra, who, upon losing one head, would regenerate two, the solution of one gerontological dilemma results in others still to be resolved. Indeed, some of the individual's ultimate problems of aging will only be solved through death. In other words, rather than devoting our energies and philosophical efforts to endeavors which seek to attain that will-o'-the-wisp, agelessness, the Public Health Service is fostering the approach which seeks to preserve optimal well-being throughout the natural life of the individual.

Delegates of the States and territories of the United States will meet in Washington, D.C., for the White House Conference on Aging on January 9 to 12,1961 . This will be a nationwide attempt to further delineate current problems in gerontology and formulate recommendations for action. The postconference report to the President of the United States will summarize the information highlighted by the conference.

\section{Hearing Impairments in the United States}

The relative frequency of hearing impairments in the United States rises rapidly with advance in age, according to a report by the U.S. National Health Survey on "Impairments by Type, Sex, and Age, July 1957-June 1958." The frequency increases in the following manner :

\begin{tabular}{|c|c|}
\hline $\begin{array}{l}\text { Age period } \\
\text { (years) }\end{array}$ & $\begin{array}{c}\text { Rate per } 1,000 \\
\text { persons }\end{array}$ \\
\hline All ages_. & $-\quad 34.6$ \\
\hline Under 25 & 7.9 \\
\hline $25-44$ & $\ldots \quad 20.6$ \\
\hline $45-64$ & $\ldots 2.2$ \\
\hline $65-74$ & - 129.2 \\
\hline
\end{tabular}

More than two-fifths of the estimated 5,800,000 people in the Nation with impaired hear- ing are 65 years or over, an age group constituting one-twelfth of the total population. More than half a million people under 25 years and nearly a million in the age group 25-44 years are affected by such impairments.

Other findings are that hearing difficulties are more common among males than among females; 40 out of 1,000 males have such impairments, a rate one-third higher than for females.

The higher prevalence rate for males may reflect their greater exposure to accidents and noise hazards in industry. In fact, the proportion of hearing impairments traced to injury is one-fifth among males compared with one twenty-fifth among females. 